УДК: $101.1+101.2+101.9$

\title{
Мария ПРЕДЕИНА
}

\section{ДОЛЖНА ЛИ ФИЛОСОФИЯ БЫТЬ МАССОВОЙ}

Статья отталкивается от факта разрыва между философом-преподавателем и студентом. Будущие инженеры и даже жмурналисты живут в другой системе образов (понятий), для них «священные» имена - будь то Аристотель, Гегель, Маркс (продолжите на свой вкус) - лишены

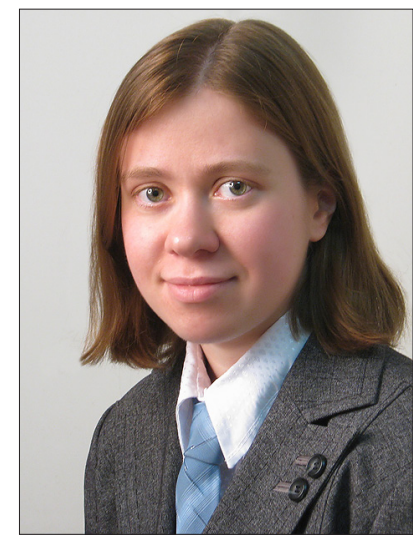
изначального очарования. Цель автора, почти по Спинозе, не печалиться, не морализировать, а понимать резоны критикующей стороны. В статье «протестная масса» разделена на «простецов» и не«простецов». (Это деление задает структуру работы). «Простеи» тоскует по черно-белому миру, а не-«простец» устал от «избитых» истин. Обе критики вращаются вокруг «деконструкции», хотя берут «деконструкцию» с разными знаками. Философу нетрудно пойти навстречу «простеиу» и возродить догму, повторить Платона или «диамат». Но в этом шаге философия превращается в идеологию, а сам философ - в «ученого педанта». Гораздо труднее ответить на запросы не-«простеца», научить и научиться свободе мышления, критицизму, умению смотреть на обычное с необычной точки зрения.

Ключевые слова: критика, философ, «простец», не-«простец», догма, «деконструкция», эпистема, дружеский союз, университет.

Философия не в чести. Просится уточнение - сегодня. А не к месту: когда философия была в чести? Пусть Фалес - первый философ, тогда фалесова служанка - первый критик: «Эх ты Фалес! - говорят, попрекала она хозяина. - Не видишь того, что под ногами, а думаешь познать то, что на небе» (Диоген Лаэртский, 1986: с. 65). Что ж, Фалес все-таки предскажет затмение Солнца, а философ «вообще» нет. В этом-то новация: сегодня философу все труднее оправдать себя.

Перед нами как будто старый вопрос предмета: раз гонят из природы, из истории - дескать, уступи науке - чем тогда заняться? Мышлением. Ан, нет: из мышления тоже гонят. И не из-за хитроумных психофизиологических «штук» (эти «штуки» не заменят логику), а потому что философия, диктуя метод, много на себя берет.

«Присваивающее господство» (Деррида, 2012: с. 17), как пишет Деррида, - вот чем не угодна философия. 
Прежде критика целила в данную философию во имя какой-то новой, но тоже философии. Теперь - в философию «вообще», в систему, метод - в то, что подминает под себя мир (хотя только в понятии).

А что философ «по профессии»? Обычно сердится. Но: Юпитер, ты сердишься - значит, ты не прав.

\section{«Простец» критикует}

«Демокрит вводит понятие «атом»...»- «А нам это зачем?» - один из вариантов диалога с «простецом» на студенческой скамье. Инвариант тут: «зачем?». А в самом деле...

В чем практическая польза философии? - этот вопрос вместе с ответом «ни в чем» уже звучит в смехе фалесовой служанки. Может, чтобы ответить служанке, Фалес проворачивает знаменитое дело с маслодавильнями. Хороший ответ, но дан он за пределами философии. А можно ли ответить так, чтобы остаться в поле философии - раз; и быть понятым «простецом» - два?

Чтобы решить, нужен диалог. Думаю, диалогом нас снабдит Аристофан, точнее, его комедия «Облака». («Думаю...» - субъективное измерение, но ничего не поделаешь.)

Аристофан сводит «простеца», маска Стрепсиад, с философом, маска Сократ (не исторический Сократ, а маска, как в комедии дель арте). Конечно, Сократ у Аристофана снижен, несколько приземлен, но потомуто идет диалог. Иначе было бы, как в еще одном случае из практики: «Говорите проще, мы слов не понимаем...», - кричат с задних рядов. Хотя в древней комедии тоже так было: «С чего же мы приступим к изучению // тех тайн, которых раньше ты совсем не знал? - вопрошает Сократ. - С размеров, с диалогов иль с ладов, - скажи?» - «По мне, начнем с размеров, - выбирает Стрепсиад. - Вот недавно лишь // надул меня торговец на две меры ржи». - «Не в этом дело; отвечай, какой размер, // трехмерный иль четырехмерный, любишь ты». - «Я - четверик. Четыре меры полные» (Аристофан, 1970: с. 380). Что делать? Бедолага Сократ вынужден говорить проще - к примеру, объяснять «механизм» грома через урчанье в брюхе. Но все равно «коммуникация» буксует, ведь цели у «масок» разные, масштаб разный. Стрепсиад идет в «мыслильню», чтобы научиться «кривой речи» и не платить долгов, а Сократ толкует ему про облака да про облака. Оба не довольны друг другом, и оба правы в своем недовольстве.

Поставить бы тут точку, но у Стрепсиада есть сын Фидиппид, более способный ученик. Дадим слово отцу и сыну-«философу», посмотрим, как они сговорятся: «Я занялся сложеньем слов и мыслей изощренных. 
// И доказать могу, что сын отца дубасить вправе, - выдвигает тезу Фидиппид. - И вот о чем тебя спрошу: меня дитятей бил ты?» - «Да, бил, но по любви, добра тебе желая», - спешит в ловушку отец. - «Что же, // я добра тебе желать не вправе, точно так же // и бить тебя, когда битье - любви чистейший признак?» - «Но нет обычая нигде, чтоб сын отца дубасил». - «А кто обычай старый ввел, тот не был человеком, // как ты да я? Не убедил речами наших дедов?» (Аристофан, 1970: с. 422). По Аристофану, это - последняя капля, дальше сжечь «мыслильню», что и делает Стрепсиад. Пожалуй, исторический Сократ тоже чужд комедиографу - скорее, обвинителю, чем защитнику на суде. Но текст говорит больше, чем автор.

Суть диалога не в бить/не бить, а в том, что каждое явление, каждый обычай можно (и нужно) рассматривать с непредсказуемой, необычной точки зрения. Сказал кто-то $A$ - говори не- $A$.

Это бросает свет на якобы глупые диалоги: «Кто из животных мужеского пола? А?» - спрашивает Сократ. - «Знаю, не сошел с ума. // Козел, кобель, жеребчик, хряк, баран, ну, дрозд». - «Вот видишь, вздор несешь ты. Ведь и самочку, // как и самца, дроздом ты называть привык» (Аристофан, 1970: с. 381-382). Именно - привык... Потому нужна «деконструкция» привычек, только через нее открывается новое. Ведь Демокрит (вспомним вопрос из практики) вышел на свои атомы тоже потому, что мыслил непривычно. Этим он интересен.

\section{«Философ» спешит навстречу}

Философ у Аристофана делает большую работу «деконструкции». Но остается чужд и «простецу», и комедиографу. Почему? Может, оттого, что «простец» не знает ладов, но комедиограф-то знает. Дело не в знании, а в привычке - в чем-то предрациональном, как в страхе бескрайнего пространства и любви к уюту. А еще часто мысли нужны подпорки: говоришь сам - вдруг ошибся, цитируешь - значит, прав. А «деконструкция» лишает нас авторитетов. Ну, а пока не лишила, процитируем Адорно: «Люди не знают другого счастья (в т.ч. и счастья мыслить), кроме как счастья иметь опору в чем-то, быть несвободными на протяжении многих и многих лет» (Адорно, 2003: с. 41). Хорошо сказано, а еще Адорно включает философов в «люди», что верно не только формально.

Философ тоже не любит игру в $A /$ не- $A$, в антитетику, и спешит укрыться под уютной кровлей «практического разума» или «диалектического синтеза». У нас это обычно ассоциируется с «противоречием между системой и методом Гегеля». Пока классик обменивает $A$ на не- $A$, все здорово, его метод дает эстетическое наслаждение, словно поэзия. 
(В поэзии, если верить Бодрийяру, источник наслаждения в том, что элементы языка - слова, слоги - обмениваются, отвечают друг другу (Бодрийяр, 2000: с. 341).) А потом раз и «остаток», какое-нибудь пресловутое прусское государство. Откуда? Вряд ли, дело в угодничестве перед королем. Слишком вульгарно. Нет, скорее, в желании «снять» противоречие «здесь и сейчас», даже если это невозможно (ведь история не заканчивается в тот миг, как автор садится за текст).

«Снимать» вопрос, вопреки всему, - значит, строить систему. То есть ограничивать пространство, идти назад в привычный, лишенный неопределенности мир. Тут - на почве системы - философ подает руку «простецу». Уже Платон возрождает догму. Так, что Аристофан поджигает «мыслильню» (в комедии) по ошибке - не вслушался в новые веяния, не узнал настоящего Сократа. Но, конечно, знаковая встреча двух «масок» - «диамат», массовая философия.

Чтобы встреча обрела голос, введем еще две «маски», на этот раз не эллинов, а активистов Николая Островского. «Простец» - молодой партиец - сдает экзамен в Коммунистический университет. «Скажите, товарищ Панкратов, какие сведения вы имеете по философии?» - задает ему вопрос «философ»-экзаменатор. Ну, юнец припомнил софистов да Диогена с бочкой и как «жахнет»: «Философия - одно пустобрехство и наводка теней. Я, товарищи, этой бузой заниматься не имею никакой охоты» (Островский, 1967: с. 627). Комиссия в хохот. А почему? Та же аристофановская путаница: товарищ Панкратов, как когда-то Стрепсиад, думает, что философ научит его смотреть на обычные вещи под необычным углом зрения, иначе, на языке «простеца» - наводить тень на плетень. Ан, нет: ему предлагают систему, выстроенную по этакому «геометрическому методу», и расчерченный «в клеточку» мир. Товарищ Панкратов, занимайся «этой бузой» смело - твой черно-белый мир ничто не пошатнет!

Да, «Диамат» - система, вопреки всему, что Энгельс говорит против систем. То есть вопреки воле «основоположников». Неожиданный поворот: система строится вопреки строителям, лезет изо всех щелей, стоит лишь отвернуться. Даже у самого Энгельса «Людвиг Фейербах» против систем, а «Анти-Дюринг»- система.

\section{Должна ли философия быть массовой?}

Ответ уже предугадывается из случая «товарища Панкратова», но дадим слово эксперту по массам: «Случайность, пронизывающая реальность, есть именно то, что массы отказываются признать, - пишет Арендт. - Массы предрасположены ко всем идеологиям, потому что они 
объясняют факты как простые примеры законов и отвергают случайные стечения обстоятельств, предполагая всеобъемлющую силу, которая должна лежать в основе каждого случая» (Арендт, 1996: с. 464). Просветители думают: тяжко втолковать, что есть закон. Арендт же, наоборот, - что есть случайность. Кто же прав... А что если вспомнить споры в физике XX века: есть - как мы помним - принцип неопределенности, а есть Эйнштейн, который хочет определенности. Хочет и точка. Эйнштейн (!), который до того смешал пространство-время. Что говорить о массах? Стрепсиад верит в Эриний, а товарищ Панкратов, конечно же, поверит в законы «диамата»: у закона тут разные имена, но общая функция.

Философу не трудно шагнуть навстречу массам, построить систему, онтологию. Но в этом шаге плоды его труда станут идеологией. То есть перестанут быть философией. Переход в массы значит, что философ больше не играет, не ищет парадоксов, а «усредняет» себя, служит не образованию, а «полу-образованности» (Брижнік, 2015), этой предпосылке тоталитарных идеологий. Есть Адорно, а есть какой-нибудь академик Александров, автор учебников «диамата» в 1950-х: база у них общая (Гегель, Маркс), результат разный.

Что в итоге? Философ часто сетует, что не понят «простецом», а философия не в чести. Зря: на то она - философия. (Разумеется, «простец» может перестать быть «простецом» и полюбить игру ума. Но это - его, «простеца», желание).

\section{Не-«простец» критикует}

Философия не должна быть массовой, а философ не обязан оправдывать себя перед «простецом». Но философии следует говорить с каждым, а философу - оправдать себя в глазах не-«простеца».

Итак, в разговор вступает новая «маска»- не-«простец».

В Греции тот, кто осознает нужду в воспитании самого себя, слушает разных философов, потом - выбирает и тем признает кого-то Учителем. В клубке горизонтальных связей, в общении свободных людей некто учитель потому, что его признают ученики: сначала признание - потом воспитание. Ученик сам отвечает за сделанный выбор, а философу достаточно обнажить себя, сказав: «Вот я, вот мое богатство: хочешь - бери, не хочешь - не бери. Но если берешь, будь тем же, что я». Так, по рассказу Диогена Лаэртского, Кратет, сбросив кинический плащ, отвечает Гиппархии - девице, пожелавшей стать его женой и ученицей (Диоген Лаэртский, 1986: с. 244). Все просто, по-аттически. 
В Греции ученик (в отличие от фалесовой служанки) уважает учителя потому, что сам его выбрал.

Иначе в средневековом университете. (Философ, мой современник, не думай, что прежние школяры были лучше. Они были хуже.) В мире вертикальных связей, в котором ограничен выбор, ученики не уважают учителя. Или: университет как форма организации вертикальных связей уже не обеспечивает своим членам того, ради чего, в конечном счете, создают любой социальный институт - любви, дружбы, уважения. («Любовь, дружба, уважение, - пишет Бойченко, - цели, ради которых люди создают социальные формы разного размера и конфигурации, а социальные институты и критическое мышление - те средства, которые обеспечивают наилучшее воплощение этих целей в жизни людей» (Бойченко, 2014: с. 83).)

Поэзия вагантов, позднее - плутовской роман: вся эта литература тиражирует образ «ученого педанта». Но возьмем что-то конкретное «Письма темных людей», пародию, сочиненную гуманистами.

Магистр «свободных искусств» сетует: «А у магистров такая скудость в учениках, что просто одна срамота. Помятую доныне, что прежде, когда магистр шел в баню, за ним следовало более учеников, чем теперь по праздникам, когда идут в церковь. <...> А в прошлый раз, когда производили в бакалавры, магистры толковали об том, что некоторых надобно провалить. Я же сказал: «Этого никак нельзя. Ибо, ежели провалим хоть одного, впредь никто не захочет держать экзамен или учиться на бакалавра, а все перейдут к поэтам». И мы всем оказали снисхождение» (Письма темных людей, 1971: с. 497). Что-то знакомое: провалил - потерял того, кто идет за тобой в баню; провалил - потерял деньги, что идут за студентом. Нам нужны студенты, а мы студентам?

В «Письмах» открыт не-аттический тип легитимации: уважение покупают за оценку, точнее, пытаются купить. Вот диалог: «Ну, погоди мне тыкать, - возмущен магистр, - я тебе сие попомню на экзамене». «Плевать я хотел на степень бакалавра» (Письма темных людей, 1971: с. $498)$, - отвечает ученик. Все, и провалить нельзя, иначе факультет обезлюдит.

Перед нами два способа легитимации - через воспитание (в дружеском союзе) и через оценку (в иерархии факультета). Гуманисты, авторы «Писем», критикуют второе ради первого.

Философия Возрождения живет вне университетов - в дружеских кружках (вроде Платоновской академии Фичино), при дворе артистичных властителей (вроде Лоренцо Медичи). Это - история.

Сегодня у философии нет других форм институализации, кроме университетов. Но иерархия университета не способствует искренности: 
«автомат» будет?», «а Вам, как надо?» - инварианты новых и старых времен. А значит, наша проблема: как, не будучи выбранным учеником, заручиться его дружбой; как вопреки иерархии (системе оценок, экзаменов) уйти от тотальной лжи (вездесущих шпаргалок, чужих слов) - то есть, как при внешней нормативности установить внутреннюю связь.

Нормативность - убежище «простеца»: пусть учитель скажет, как - я повторю. А не-«простец» из-за этой же нормативности уклоняется от беседы, заранее ожидая «избитых» истин.

Вернемся к «Письмам». Магистры и гуманисты той поры живут в одной системе образов, с общими центрами притяжения: ветхозаветные времена, античность. Но как они далеки друг от друга! Разделяет их отношение к авторитетам. Поясню на примере. «Зане и поелику имеете вы всенепременное желание слышать новости - в согласии с Аристотелем, каковой глаголет: «Все люди от природы стремятся к знанию», посему я...» (Письма темных людей, 1971: с. 405), - пишет один магистр другому. По-моему, неплохо: автор - эрудит. Хотя сочиняют-то в подражание магистрам гуманисты, а потому в этих словах должно быть что-то комическое. Задумаемся... При чем тут Аристотель? Ни при чем: автор преподносит банальность, но от имени Философа; у тезы нет развития, она не подстегивает мысль; цель автора показать, что он знает Аристотеля, еtс. Этот Аристотель - мертвый авторитет. (То же в наши дни, когда нудное перечисление имен с тезами убеждает студента только в одном: лектор знает чудные имена.) В том, в чем магистр видит ученость (разве зря молодость ушла на «зубрежку»?), гуманист видит нечто обратное: все-таки цитата хороша только там, где она помогает думать; авторитет к месту только там, где он приоткрывает тайну мысли, вводит нас в «мастерскую» идей.

Сегодня студент - будущий физик или инженер - не чувствует почтения к Аристотелю только потому, что это - Аристотель. Образы прошлого меркнут, и потому лектор должен объяснить - a, может, и сам понять - чем тот же Аристотель полезен (или не полезен?) в деле научения мыслить. Умный студент готов мыслить, но не «зубрить».

$\mathrm{K}$ «Письмам». Магистры защищают авторитет «свободных искусств» тем, что отсылают к авторитету своей коллегии. Один магистр неверно перевел греческое слово, и поэт сказал ему: «Вы не грамматик». «Вот тут я возрадовался, теперь-то притяну его к ответу, - сообщает обиженный, - потому как милостью божией я имею степень магистра, и, ежели по мнению всего университета я довольно учен, то уж на одного поэта во мне станет учености, ибо целый университет больше, чем один поэт» (Письма темных людей, 1971: с. 425). Не трудно понять, что такая арифметика не работает: то, что «все» считают магистра ученым, не делает его 
таковым, зато делает «всех» - не-учеными; сами «свободные искусства» терпят поношение из-за магистра, поэт не виноват.

Так же точно не работает ответ: «Учите философию потому, что она в учебном плане. Это - решение кафедры, вуза». Не прикрыть философию авторитетом «корпорации»: студент не благоговеет перед институциями.

\section{Философ спешит навстречу?}

Снова перед нами «деконструкция», но подходим к ней с другой стороны: то философ защищал «деконструкцию» перед «простецом», а теперь философ уступает критике не-«простеца». Роли подвижны: философ, прикрывающийся авторитетами, превращается в «темного человека» («ученого педанта»), а ученик, критикующий авторитеты, в философа. Эта смена ролей происходит в «Письмах». Словом, быть философом - не значит получить синекуру, скорее наоборот.

К чести философии: в ней живет тяга к обновлению.

«Деконструкция» - такой же момент в истории философии, как «конструкция»; это - два момента, сменяющие друг друга: точнее, пока сменяющие. Нынешняя новация в том, что неясно (пока?) возможна ли очередная «конструкция». Об этом подробнее.

«Письма» начинают «деконструкцию» так же, как партия - «перестройку»: не затем, чтобы разрушить, а чтобы очистить «парадигму». Гуманисты согласны с тем, что Фуко описывает, как поиск сходства языка с вещами. («Язык, - характеризует данную эпистему Фуко, - это раздробленная, внутренне расколотая и видоизмененная природа; это - тайна, несущая в себе доступные расшифровке знаки того, что они обозначают» (Фуко, 1994: с. 72).) Иначе, с точки зрения гуманистов, магистры в рассуждениях, вроде: «всадник» происходит от глагола «саднить», потому что от верховой езды в теле саднит; а «патриций» то же самое, что «под тридцать», ибо всякому патрицию когда-нибудь да бывает под тридцать лет» (Письма темных людей, 1971: с. 424), обнаруживают глупость не в том, какую эпистему используют, а в том, что не знают толком ни классической латыни, ни греческого, ни древнееврейского. Для тех и других язык - равно авторитет. Но результат, полученный к XVII-му веку, - «деконструкция» не перегибов, а самой эпистемы: о вещах повествуют не слова, а наука.

Наука предстает основой основ, и философия вступает в борьбу за право тоже зваться наукой; философия оправдывает себя через авторитет науки; и философия же берется обобщать науку. (Автору самому доводилось излагать «Философию естествознания» и лезть по мере сил в 
квантовую механику и Большой Взрыв. Единственное, что его извиняет - это работа с текстами физиков как с текстами).

Но в нашей (очередной) «деконструкции» философия теряет научный тыл: Summa естествознания, как в «диамате» - уже анахронизм; если что остается от науки, то это динамика научного знания (та самая работа с текстами для уяснения эпистемы).

Думаю, философия может изучать то, как развивается научное знание («научные революции», «парадигмы»), но это не делает ее наукой. Есть некие неустранимые особенности, эстетическое измерение - тот странный феномен, когда ты не согласен с выводами («остатками») философа, но захвачен манерой его письма. Я (тут уместнее сказать от первого лица) не думаю, что есть «Абсолютная идея», но это не мешает мне любить манеру письма Гегеля: он держит читателя в напряжении, когда нельзя расслабиться, а нужно следить за каждым шагом в приключении идеи так, словно идея - Шерлок Холмс. (Из чего не следует, что философия - искусство. Может, философия - философия?)

Как бы то ни было, друг за другом исчезают бесспорные основания то, на чем возводят «конструкцию». «Сам сказал!» - не актуально. «Наука доказала» - тоже нет. Может, новые основания еще выскочат, как черт из табакерки: ведь не думали же поборники древних языков, что их (вместе с Доктором Святым, т.е. Фомой) вытеснит наука. Но пока этих новых основ не видно, и к лучшему.

\section{Что в итоге?}

Подойдя к «Деконструкции» с двух сторон, посмотрев глазами «простеца» и не-«простеца», было бы неверно закончить: философия должна то-то и то-то; ведь единственно, чем философия оборонялась от догматизма первого и оправдывала себя перед ироничной усмешкой второго была критика, в том числе в собственный адрес. Наконец, указать, что философия «должна» то-то и то-то, возможно лишь в контексте «парадигмы», а «парадигмы»-то нет. Это и есть итог.

Философ выбирает свою «парадигму», будучи готовым к тому, что та отнюдь не господствующая (уже плюрализм!), а потому его следующий шаг - защита выбранной «парадигмы» в споре. Он вынужден смотреть на свою «возлюбленную» чужими глазами, выходя из уютного убежища догмы. Либо философ не выбирает «парадигму», а работает за пределами всех «парадигм»; он, как «эпистемологический анархист» подбирает по своему вкусу то одно, то другое, экспериментирует, ищет интересные «Повороты». Философствование - уже не Summa против кого-то, не 
опровержение неких X, не понявших «вечных истин», а скорее включение в творческий процесс разных «рациональных зерен».

Что бы философ ни выбрал, в его выборе живет личностное начало, а борьба за свой выбор требует умения спорить по существу, искать аргументы. В философию возвращается жизнь - та, что привлекала некогда свободных людей. Как во времена софистов? Но антитеза-то им - государство Платона.

\section{Литература:}

1. Адорно Т. В. Негативная диалектика [пер. с нем. Е.Л. Петренко]. - М.: Научный мир, 2003. -363 c.

2. Арендт Х. Истоки тоталитаризма [пер. с нем.]. - М.: ЦентрКом, 1996.- 672 с.

3. Аристофан. Облака [пер. с древнегреч. А. Пиотровского] // Библиотека всемирной литературы: в 200-х тт. - Т. 5. - М.: Художественная литература, 1970. - С. $347-426$.

4. Бодрийяр Ж. Символический обмен и смерть [пер. с фр.]. - М.: Добросвет, 2000. -387 c.

5. Бойченко М. Історичне становлення інституційних засад критичного мислення // Філософія освіти.Philosophy of Education. - K., 2014. - № 2 (15). - C. 80-97.

6. Брижнік В. Вступ до філософії освіти Теодора Адорно // Філософія освіти. - К., 2015. - № 2 (17). - С. 119-131.

7. Деррида Ж. Тимпан [пер. с фр. Д.Ю. Кралечкина] // Деррида Ж. Поля философии. - М.: Академический проект, 2012. - С. 9-23.

8. Диоген Лаэртский. О жизни, учениях и изречениях знаменитых философов [пер. с древнегреч. М.Л. Гаспарова]. - М.: Мысль, 1986. - 574 с.

9. Островский Н. Как закалялась сталь // Библиотека всемирной литературы: в 200-х тт. - Т. 194. - М.: Художественная литература, 1967. - С. 421-751.

10. Письма темных людей [пер. с лат. В. Хинкиса] // Библиотека всемирной литературы: в 200-х тт. - Т. 33. - М.: Художественная литература, 1971. - С. 395-505.

11. Фуко М. Слова и вещи. Археология гуманитарных наук [пер. с фр. В.П. Визгин, Н.С. Автономова]. - СПб.: А-cad, 1994. - 407 с.

\section{Марія Прєдєіна. Чи повинна філософія бути масовою?}

Стаття відштовхується від факту нерозуміння між філософом-викладачем і студентом. У статті вказана різниця між резонами критиків. «Простак» сумує, що не існує чорно-білого світу. А не-«простак» втомився від банальностей. Філософу неважко відродити догму, але тоді філософія перетворюються на ідеологію, а філософ - на «вченого педанта». Важче відповісти на запити не-«простаків» і навчити (навчитися) свободі мислення, критицизму.

Ключові слова: критика, філософ, «простак», не-«простак», догма, «деконструкція», епістема, союз друзів, університет. 


\section{Maria Predeina. Must Philosophy be Mass doesn't it?}

The articles is based on the existence of a kind of gap between a philosopher and students. Future engineers and even journalists live in other system of ideals. The aim of author is not reasoning in the categories «of due», but study that, why students criticize philosophy. The are two groups of critics - simpletons and nonsimpletons. A simpletons criticizes because a philosopher destroys the world clarity. A non-simpletons criticizes because sometimes a philosopher teaches the dogmas. Both criticisms determine the attitude toward a deconstruction. For a philosopher it would be easier to follow the demands of the simpletons and to revive a dogma. But in this case philosophy would be converted into ideology. Therefore a philosopher must answer upon requests non-simpletons: teach (and to learn) to freedom of thinking, ability to look at the generally accepted from the unusual point of view.

Keywords: criticism, philosopher, simpletons, not simpletons, dogma, deconstruction, episteme, friendly alliance, university.

Предеина Мария Юрьевна - кандидат философских наук, журналист, публиковалась в журналах Politeka.net, «Грушевского, 5».

E-mail: predeina_maria@mail.ru

Predeina Maria - candidate of philosophical sciences, journalist, wrote for Politeka.net, «Grushevskogo, 5». 